\title{
Knowledge and Practices of Neonatal Resuscitation by Health Providers in Côte d'Ivoire
}

\author{
Cisse Lassina ${ }^{1}$, Joseph Gnegneri Ouattara1, Kouadio Vincent Asse ${ }^{2}$, Line Couitchere1, \\ Jacob Enoh ${ }^{1}$, Kouadio Richard Azagoh', Jean-Jacques Attebi' ${ }^{1}$, Soumahoho Oulai ${ }^{1}$ \\ ${ }^{1}$ Paediatric Ward of University and Teaching Hospital of Treichville, Abidjan, Côte d'Ivoire \\ ${ }^{2}$ Paediatric Ward of University and Teaching Hospital of Bouake, Bouake, Côte d'Ivoire \\ Email: lbacongo@yahoo.fr
}

How to cite this paper: Lassina, C., Ouattara, J.G., Asse, K.V., Couitchere, L., Enoh, J., Azagoh, K.R., Attebi, J.-J. and Oulai, S. (2017) Knowledge and Practices of Neonatal Resuscitation by Health Providers in Côte d'Ivoire. Open Journal of Pediatrics, 7, 149-155.

https://doi.org/10.4236/ojped.2017.73018

Received: June 28, 2017

Accepted: August 5, 2017

Published: August 8, 2017

Copyright (c) 2017 by authors and Scientific Research Publishing Inc. This work is licensed under the Creative Commons Attribution International License (CC BY 4.0).

http://creativecommons.org/licenses/by/4.0/

\begin{abstract}
Côte d'Ivoire ranks third among African countries with the highest neonatal mortality rate $(38 \%)$. Perinatal asphyxia is one of the major causes of neonatal mortality. In its severe form, it imposes an efficient neonatal resuscitation in the birth room. This can only be done when the proven competence of the staff in charge of the newborn and the availability of the appropriate equipment are met. What is the situation in the birth facilities of these two challenges for the response to the high rate of neonatal mortality in Côte d'Ivoire? Method: It is a cross-sectional study, which took place from March 28 to July 28, 2016, in three health districts of Côte d'Ivoire (Bouaké, Gagnoa, Yopougon). Public health structures offering delivery activities were selected. Based on a fact sheet, the practitioners present have been interviewed and a direct observation of the organization and equipment set up to perform neonatal resuscitation in the birth room has been done. In addition, an observation grid made it possible to evaluate the practical skills of providers in neonatal resuscitation on a newborn mannequin. The data were entered using the Epi-Info 7 software. Based on the data collected, we determined the numbers and frequencies of the responses of the target agents of the survey. Results: The membership structures included 46 first contact health facilities (FCHFs) and 4 reference hospitals (HRs). The heating system, mucus suction, oxygen, timers and self-inflating balloons were available in $\mathrm{HR}$ and in six, eight, four, 34 and 10 FCHFs respectively. The 253 midwives surveyed came from Bouaké (86), Gagnoa (62) and Yopougon (105). They had a seniority of at least eight years. Their knowledge for newborns' care was acquired in initial training ( $75 \%$ of cases). They knew the golden minute in $95.6 \%$ of the cases. Inadequacies in the recognition of risk situations, useful equipment and in the execu-
\end{abstract}


tion of neonatal resuscitation steps were noted. Conclusion: The survival of the newborn is still very worrying in Côte d'Ivoire. An analysis of the results of this survey shows that many challenges remain not only at the structural level but also at the level of quality of care.

\section{Keywords}

Knowledge, Midwives, Neonatal Resuscitation, Practice

\section{Introduction}

Neonatal mortality is still high worldwide, particularly in resource-poor countries, where it accounts for $44 \%$ of deaths among children under five years of age [1] [2] [3] [4].

Côte d'Ivoire is one of the countries with high neonatal mortality rates, 38 live births [5]. In ranking, it is the third among the African countries with the highest neonatal mortality rate. The main causes of peri- and neonatal deaths were complications of prematurity, perinatal asphyxia and infections [6].

In Côte d'Ivoire, studies of knowledge and practices in the neonatal resuscitation of health providers are rare. The aim of this study is to assess the level of knowledge of healthcare providers involved in birth structures, in neonatal resuscitation in particular and to identify the elements of the system set up for its successful implementation while describing the general organization of care of the newborn in the birth room.

\section{Material and Method}

It is through a cross-sectional study, which took place from March 28 to July 28 , 2016 and concerned three health districts of Côte d'Ivoire. These three health districts out of the 82 in the country were selected because of the size of their population on the one hand and the prevalence of the neonatal mortality rate on the other (upper than national level). It is firstly Yopougon, the most populous of the ten municipalities of Abidjan, the economic capital of Côte d'Ivoire. Secondly Gagnoa, the capital of the Gôh region and thirdly Bouake the second largest city of Côte d'Ivoire. Public health structures offering delivery activities were selected. Investigative authorizations were obtained from the local health authorities with the absolute guarantee of ethics. Based on a fact sheet, interviewed by the practitioners present and a direct observation of the organisation and equipment set up to perform neonatal resuscitation in the birth room. In addition, an observation grid made it possible to evaluate the practical skills of providers in neonatal resuscitation on a newborn mannequin.

The first interpretations of the results of these sheets led to a debriefing on the site and then made it possible to better guide the exchanges during the skillsbuilding sessions. 
The data were entered using the Epi-Info 7 software. Based on the data collected, we determined the numbers and frequencies of the responses of the target agents of the survey. To measure the association between the periods of experience and the level of knowledge of healthcare providers, we determined the Odds Ratios with a confidence interval (CI) at 95\%.

\section{Results}

\subsection{Socio-Demographic Characteristics of Practitioners}

Thus, of the 253 practitioners, 86 came from Bouaké, 62 from Gagnoa and 105 from Yopougon. Females accounted for $99 \%$ of all the participants. Midwives accounted for $98 \%$ of whom. This represents $38 \%$ of the midwives in these areas. The others participants were 4 general practitioners and a caregiver. Those ones were from pediatric departments.

They were all diploma holders with a median age of 29 years (minimum $=20$; maximum $=50)$. The periods of experience were an average of eight years ( minimum $=2$ years; maximum $=29$ years $)$.

The midwives usually worked alone at their post in the delivery room in $54.2 \%$ of cases.

\subsection{Practitioner's Health Structures}

They consisted of 17 Urban Health Centers (UHCs), 5 community-based Urban Sanitary Centers (C-BUSC), 2 maternal and child care centers (MCCC), 9 Rural Health Centers (RHC), 2 general hospitals $(\mathrm{GH})$, a regional hospital centre (RHC) and a hospital and university center (HUC). While the first 4 types of centers are first contact health facilities (FCHFs), the last three are the reference centers $(\mathrm{RC})$.

\subsection{Equipment Available for Neonatal Resuscitation}

The heating system (consisting of a resuscitation table or a radiant table) was available at the RC). As for the FCHFs, six had a radiant table (13\%).

Respiratory devices, electrical vacuum cleaners and self-inflating balloons found in all reference structures were available in $15.2 \%$ and $21.73 \%$ of FCHFs, respectively. In the other structures, the aspiration of the mucus was done with traditional suction devices (73\% of the cases) while the ventilation was done using Pinard stethoscope, by oral insufflation of the provider. Oxygen was accessible in all reference structures. In terms of first contact structures, overall $8 \%$ were provided; these were found in $60 \%$ of the cases in the FCHF in Yopougon (Abidjan), one in Gagnoa and none in Bouake region.

The timers for the rating of the APGAR index in the delivery rooms and for monitoring the time taken to care for the newborn in the birth-room and in particular the golden minute, were available in Reference structures. At the FCHF level, the structures that had them were $73 \%$. 


\subsection{Collaboration Doctor and Midwife}

It was at the University Hospital Center in Bouake that a paediatrician was sometimes called in the birth-room. In other facilities, newborns are referred to paediatric wards or directly transferred to a referral hospital. Then, this decision is taken exclusively by the midwife.

\subsection{Knowledge and Skills of Birthing Room Staff}

Knowledge for newborn care was acquired during initial training (75\% of cases), those obtained in-service ( $20 \%$ of cases) or in other training sessions $(3 \%)$. In the past two years, 40 midwives $(16.13 \%)$ had received training in neonatal resuscitation; (20 people), training workshops organised on the sidelines of the commemoration of the International Midwifery Day (2016) (6 people).

The golden minute was known to $95.6 \%$ of midwives. The midwives were able to determine one situation at risk for neonatal resuscitation in 79 cases $(31.8 \%)$, two in 63 cases $(25.4 \%)$, three and four in 33 Cases $(13.3 \%)$ each. In addition, six subjects were able to list the five situations requested. Seventeen midwives (6.8\%) had given a correct answer when asking about three conditions for the success of neonatal resuscitation. The proportion of practitioners, who listed fewer than four items needed for neonatal resuscitation, represented $40 \%, 64 \%$, $50 \%$ in Bouake, Gagnoa and Yopougon's reference hospitals. But this proportion was 33\%, 67\% and 20\% respectively in Bouaké, Gagnoa and Yopougon's FCHFs. For the stages of neonatal resuscitation, 17 midwives responded fairly $(6.8 \%)$. In $43.2 \%$ (107 midwives) they did not know them. If for 66 of them, neonatal resuscitation began with the release of the upper airway, for 18 (7.3\%), cardiac massage should be done straight away in the first place. The results of the direct observation of the practitioners during the simulations of neonatal resuscitation are recorded in Table 1. Many under-performances (Must be improved) were

Table 1. Skills of practitioners in performing neonatal resuscitation stages.

\begin{tabular}{|c|c|c|c|}
\hline \multirow{2}{*}{ Steps of newborn resuscitation } & \multicolumn{3}{|c|}{ Performances } \\
\hline & Must be improved & Executed with skill & Executed with great skill \\
\hline $\begin{array}{l}\text { Maintenance of a correct } \\
\text { temperature }\left(36^{\circ} 5 \text { et } 37^{\circ} 5\right)\end{array}$ & $\begin{array}{l}\text { Preheat linen } \\
\text { Evaluate color, breathing and heart } \\
\text { Contact skin to skin }\end{array}$ & Dry the body & Place under the heating lamp \\
\hline Release of airways & $\begin{array}{c}\text { Good positioning } \\
\text { Aspirations of secretions }\end{array}$ & $\begin{array}{l}\text { Put a block under } \\
\text { the shoulder }\end{array}$ & \\
\hline Establishment of breathing & $\begin{array}{c}\text { Touch stimulation } \\
\text { Positioning the face mask } \\
\text { Compliance with ventilation } \\
\text { procedures at the ball } \\
\text { Evaluation of the effectiveness of ventilation }\end{array}$ & & \\
\hline Provide circulation & $\begin{array}{l}\text { Check heart rate } \\
\text { External heart massage }\end{array}$ & & \\
\hline Use of medicines & Neonatal resuscitation medicines & Vitamin $\mathrm{K} 1$ & \\
\hline
\end{tabular}


noted during the execution of the different stages of neonatal resuscitation. The knowledge and skills of midwives depends on length of service $(\mathrm{OR}=2.14$ and $\mathrm{CI}=1.46-2.78$ ). However there was no difference according to the type of health care facility or the city of belonging (respectively $\mathrm{OR}=1.76$ with $\mathrm{CI}=$ $0.48-2.01$ and $\mathrm{OR}=1.10 \mathrm{CI}=0.89-1.38$ )

\section{Discussion}

This work, which was carried out for the first time on neonatal health in relation to the knowledge and practices of providers in birth-rooms in Côte d'Ivoire, was attended by a limited number of practitioners. In addition, the data were collected by an interview on the one hand and by observation during an anatomical modelling. If the first situation gives rise to a remembrance bias, the latter may not reflect reality in the birth room.

Nevertheless, it is recognised that midwives are the first line of defense against neonatal mortality [7] [8]. Particular attention should be paid to their being, knowing, knowing to be and knowing how to do. Several studies conducted in Africa and elsewhere have shown the inadequacy between their numbers and the needs of the population under their care, on the one hand, and between their knowledge and their functions, on the other [9] [10] [11]. This might be due to the absence of standardized training during the undergraduate and postgraduate courses as found in the study of Gebreegziabher et al. in Ethiopia [11].

Our study notes that midwives are relatively young and have more than five years of service. They should, therefore, be competent to provide necessary and appropriate assistance to newborns in the birth room; According to the findings of Jukkala in the USA, who observed an improvement in the performance of the paramedical staff after five years of exercise [12]. If this is not observed through our study, there may be a lack of monitoring, training (supervision, coaching) activities on the ground by the district managment teams. These activities are the cornerstone of the quality of care in the Ivorian health system. The midwife should, in principle, have additional training in the detection and managment of risk situations for the newborn and his mother [7] [13].

Poor performance is noted both in terms of equipment for newborn care facilities and in the ability of midwives to cope with the distress to which they may be confronted; this despite the high rate of newborn mortality in our country. In addition, although in more than $90 \%$ of cases, childbirths go well, however birthing rooms and the teams working there should be prepared to deal with all the contingencies of a difficult birth, both for the mother than for her newborn. Therefore the birth-rooms must have the necessary equipment, and the staff in charge of newborns and their mothers, must be sufficient in number, master of everything that contributes to safe delivery, including neonatal resuscitation activities in the birth room. This is justified by the fact that the period surrounding birth is the most at risk for mother and newborn [7]. Each year, more than $40 \%$ of maternal deaths (about 290,000) and stillbirths or neonatal deaths (5.5 mil- 
lion) occur very early in this period. These deaths occur rapidly and require rapid intervention by health personnel [4].

Indeed, virtually all structures in general and in particular the structures of the first contact lack basic equipment for the immediate care of the newborn in the birth room. Is not this, responsible for the insufficient knowledge of neonatal resuscitation stages, the conditions and the equipment essential for its proper realization? While this may be sustainable, most of the midwives interviewed keep their knowledge of the lessons learned during their pre-service formation, often purely theoretical, training. Very few of them have participated in the additional on-the-job training. This observation is also made by Ekouya et al. [10]. In their series, only $17.1 \%$ of midwives had received training in neonatal resuscitation. Does this corroborate the fact that the major players in health care have little interest in neonatal health [14]? It is also to note the very timid participation of pediatricians and assimilated, in this activity for a safe birth. Moreover, we note a very timid participation of pediatricians and assimilated, in this activity for a safe birth.

According to the low level of basic education in the efficient managment of newborn problems in the hours following birth, obstetricians and gynecologists, midwives, pediatricians, neonatologists and nurses will have to work together to promote a high level of maternal and neonatal care, through the education required both at the schools of basic health training and in the course of employment [2] [7] [13]. For example, pediatricians or general practitioners working in pediatric units should be increasingly involved in the birth rooms. Moreover, we have to increase the monitoring and coaching of midwives at their place of exercise. It is in this context that fits the new initiative of the Ministry of Health in Cote d'Ivoire, midwives mentoring. This is to increase the competence of midwives in the birthing rooms, allowing the oldest and most experienced mentor.

\section{Conclusion}

The survival of the newborn, which is today a development index of country, is still very worrying in Côte d'Ivoire. Analysis of the results of this survey shows that many challenges remain. This includes strengthening both basic and inservice training, health staff in general, but especially midwives, and provision of essential equipment (e.g., bag-and-mask device, suction) for the immediate care of newborns in distress. Thus, efforts should be made to implement the existing and proven guidelines in this area, such as the help baby to breast (HBB), basic emergency obstetric and neonatal care (BEmONC), and observation of the continuum of Care for mothers and newborns for reproduction, maternal and child health. In fact, quality care should be the central focus of efforts.

\section{References}

[1] UN Inter-Agency Group for Child Mortality Estimation (IGME) (2013) Levels and Trends in Child Mortality: Report 2013. UNICEF, New York.

[2] Darmstadt, G.L., Bhutta, Z.A., Cousens, S., Adam, T., Walker, N., de Bernis, L. and 
the Lancet Neonatal Survival Steering Team (2005) Evidence-Based, Cost-Effective Interventions: How Many Newborn Babies Can We Save? Lancet, 365, 977-988.

[3] You, D., Bastian, P., Wu, J. and Wardlaw, T. (2013) Levels and Trends in Child Mortality. Estimates Developed by the UN Inter-Agency Group for Child Mortality Estimation. Report 2013. UNICEF, WHO, the World Bank, and United Nations, New York.

[4] Lawn, J.E., Blencowe, H., Oza, S., et al. (2014) Every Newborn: Progress, Priorities, and Potential beyond Survival. Lancet, 384, 189-205.

[5] Health Ministry of Côte d'Ivoire (2013) Demographic Health Survey-Multiple Indicator Cluster Surveys 2011-2012. Rapport de synthese, page 24.

[6] WHO Côte d'Ivoire (2013) WHO Statistical Profil. http://www.who.int/gho/en

[7] New, K., Konstantopoulos, A. and Arulkumaran, S. (2014) Every Newborn: The Professional Organisations' Perspective. The Lancet, 384, e25-e26.

https://doi.org/10.1016/S0140-6736(14)60692-9

[8] Khan, K., Pattison, T. and Sherwood, M. (2011) Simulation in Medical Education. Medical Teacher, 33, 1-3. https://doi.org/10.3109/0142159X.2010.519412

[9] Karaguinsky, C. (2012) Are the Midwives Adequately Prepared for Neonatal Resuscitation during Their Studies? Gynecology and Obstetrics.

http://dumas.ccsd.cnrs.fr/dumas-00765298

[10] Ekouya Bowassa, G., Mahoungou-Guimbi, K.C., N'dinga, H., Oko, A.P.G., Okoko, A.R., et al. (2012) Knowledge and Practices of Caregivers in Neonatal Resuscitation in Brazzaville (Congo). SARANF, 17, 12-16.

[11] Gebreegziabher, E., Aregawi, A. and Getinet, H. (2014) Knowledge and Skills of Neonatal Resuscitation of Health Professionals at a University Teaching Hospital of Northwest Ethiopia. World Journal of Emergency Medicine, 5, 196-202. https://doi.org/10.5847/wjem.j.issn.1920-8642.2014.03.007

[12] Jukalla, A.J. and Henley, S.J. (2007) Readiness for Neonatal Resus Citation: Measuring Knowledge, Experience, and Comfort Level. Applied Nursing Research, 20, 78-85. https://doi.org/10.1016/j.apnr.2006.01.006

[13] WHO (2014) Every Newborn: An Action Plan to End Preventable Deaths. http://apps.who.int/gb/ebwha/pdf_files/WHA67/A67_21-en.pdf

[14] Murila, F., Obimbo, M.M. and Musoke, R. (2012) Assessment of Knowledge on Neonatal Resuscitation amongst Health Care Providers in Kenya. Pan African Medical Journal, 11, 78.

http://www.panafrican-med-journal.com/content/article/11/78/full/ 
Submit or recommend next manuscript to SCIRP and we will provide best service for you:

Accepting pre-submission inquiries through Email, Facebook, LinkedIn, Twitter, etc. A wide selection of journals (inclusive of 9 subjects, more than 200 journals)

Providing 24-hour high-quality service

User-friendly online submission system

Fair and swift peer-review system

Efficient typesetting and proofreading procedure

Display of the result of downloads and visits, as well as the number of cited articles Maximum dissemination of your research work

Submit your manuscript at: http://papersubmission.scirp.org/

Or contact ojped@scirp.org 